\title{
Fake News Galore! More Contagious than COVID-19!
}

\author{
Soham Chakraborty \\ Intern, Jawaharlal Nehru Medical College, Datta Meghe Institute of Medical Sciences, Wardha. \\ Email: sohamc1998@gmail.com
}

\begin{abstract}
The novel coronavirus disease pandemic or as we know it better, COVID-19, has ravaged society on a global scale. For the uninitiated, the disease is caused by the particular virus- Severe Acute Respiratory Syndrome Coronavirus 2 (SARS-CoV-2). It is seldom that we have a pandemic raging on that has brought with itself such a humongous scale of damage and on every single front of the human society, be it medical, economic, social or just about anything. With that it seems perfectly reasonable for COVID-19 to be at the tip of everyone's tongue. The word itself creates an aura of dread and discomfort! But there's something more sinister, and even more contagious that magnifies the ill effects of the disease, not by itself but through how we react to it! Have an idea? As with any trending topic, various social elements seem keen on spreading around and imposing on others, factually incorrect information and baseless rumours that aren't only unfruitful but also counterproductive to the cause of fighting against the disease itself.
\end{abstract}

Keywords: Fake News, Myths, Social Media, Panic, Community

\section{INTRODUCTION}

With all the fake news, false propaganda and misinformation campaigns surrounding the disease that is running rampant, through social media, news or being spread around by individuals in the real world, the social and personal damage that it has caused can be said to be on par with that of the disease itself, if not more. In light of this, we shall go through some rumours, myths and other fake news that may be making rounds related to the disease and clarify them as well.

\section{Myths and Fake News Related to COVID-19 Transmission and Deaths}

Towards the initial period of spread, it was believed that COVID-19 spread from eating bats, however there has been no concrete link established that can make an irrefutable claim of the same. Videos of people consuming bat soup in China had sprung up during the time of COVID-19 that had gone viral on social media. The fact that previously SARS was passed on to humans from bats played a bigger role in this profound fear towards the prevalent fear of bats. Some other similar rumours that have spread around is that drinking

Corona beer, a beer brand sharing the same name (as corona means crown in Spanish), eating chicken or eggs etc. can also COVID-19 transmission. But they are just rumours and should be treated as such. (1)

Due to the fragility of older and younger people, it is very much believed that only people of those age groups are affected by the disease. Young adults and adults often take it lightly with the mindset that they won't be affected. Au contraire, anyone belonging to any age group is perfectly capable of contracting the disease. However, older people or those with some other underlying disease may face more risk in terms of a higher degree of severity. But there have been cases too where people as old as 100 years old have overcome the disease.(2)

A myth that hasn't gained much ground like the others is that COVID-19 can spread through pets like cats and dogs. While the myth started with that of a dog testing positive for the disease in Hong 
Kong, there have been several more such reports adding to fears that the disease can be transmitted through pets. This has led to cases of animal abuse, mistreatment, abandonment or straight up killing of cats and dogs in many places. But there is a huge difference in just the virus being present in the animal and it having an infection. Also, in most cases, it seems that the pets had caught the virus from their owners or other humans. While, the relevance of the virus present in pets to human transmissions is still under debate, according to the CDC website, while possible, chances of animal to human transmissions are comparatively lower. The website also reports about a case of large felines at a New York Zoo displaying signs of respiratory illnesses, possibly contracting the disease from an infected employee, albeit having fully recovered. It even reports of respiratory and gastrointestinal symptoms showing up in minks across Netherland farms and a rise in mink deaths that can be related to them catching the virus from farm workers who have COVID-19. (3)

Another rumour that caused a lot of people to go lax in nature was that many sources, some of which were quite questionable, claimed that the disease would spread lesser with rising temperatures and the virus would die. This may have had its origin from the fact that other strains of the coronavirus such as MERS and SARS survived better in colder temperatures than hotter ones. Contradicting the belief, COVID-19 has managed to spread around every type of area, hot or cold, humid or dry. It is still unknown how changes in temperature will affect the disease's transmission. Similar beliefs of hot baths and hot beverages can counter the virus are baseless too. High temperature baths can harm the body and skin more than it benefits.
Given the murky origins of the disease, with most initial cases being reported from China, the country has received much flak on the global stage for its emergence and not doing enough to nip the problem at the bud. The largescale paranoia against everything that has the word China/ Chinese attached to it has led to even more rumours and disturbing behaviours as an extension of xenophobia. Many people wrongly believe that eating at Chinese restaurants can cause one to contract the dreaded disease. This has caused many restaurants to go under and there has even been a rise in cases of vandalism and violence against Chinese establishments across the globe. There are even fears that packages from China can spread the disease despite repeated reports from credible entities that the virus doesn't survive for long on such surfaces like letters and parcels that are shipped over days or weeks. Moreover, the disease itself majorly spreads from person to person contact rather than through surfaces of packages that have been in transit for so long. But the hysteria and paranoia still contribute a lot to pre-existing xenophobia. (4)

It is the responsibility of the people at the top to take care of their followers. Similarly, it is the responsibility of government bodies, entities and leaders of all nations to take proper responsibility and care when they make statements or claims about the COVID-19 pandemic, ensuring authenticity and accuracy of the same. After all the news reaches people across nations and impacts public confidence and sentiments. However, several government leaders and bodies across the globe have engaged in gross negligence in terms of reporting cases, deaths, tests conducted etc. Number of tests done being exaggerated, deaths underreported, COVID-19 deaths being passed of as comorbidities, spreading inaccurate information about various drugs 
and practices to be a perfect cure for the disease are just some of innumerous such practices that are still being done across the world. While this may keep the public's confidence in the existing government to maintain a positive image, it really hurts the country's preparedness in actually tackling the pandemic, making further estimations and forecasting the future scenarios more difficult.

It is a known truth that negative news spreads fast than their positive counterparts. Reports of COVID-19 cases and related deaths by news and media sources far exceed those of recoveries made. This is even though in reality, the number of recoveries far exceed the number of patients who have succumbed to the disease. Wide spread reports of deaths contribute to public dread and panic even though the actual mortality rate is much lesser. As per WHO, a rough estimate of the current global mortality rate of COVID-19 is between 3-4\%. While the mortality rate may be low, even $3 \%$ of a very large number, in the millions (for the population in this case) is a big number too, and any death from the disease is regrettable. However, this shows that statistically, the disease is not as deadly as it is made out to be, even though it's quite viral and easily contagious. Most patients simply go through mild and moderate symptoms and manage to recover from the disease.

As a widely enforced practice, thermal scanners are used as a detection system for COVID-19. However, this is hardly effective. Thermal scanners detect high body temperatures implying fever. Fever may be due to countless different reasons, not only COVID-19. Likewise, patients who have the disease may not even have fever or develop fever until after some number of days. So, while still appreciable, people should stop considering this practice as a sure shot way to check if someone has COVID-19 or not. (5)

\section{Myths and Fake News Related to Cures, Drugs and Preventive Measures}

First let us address one of the biggest myths that Hydroxychloroquine and Chloroquine, drugs that are used for patients suffering from malaria and some other autoimmune diseases like rheumatoid arthritis, lupus erythematosus etc., and generally considered safe too, are an all cure for COVID-19. Various leaders had endorsed the drug without sufficient scientific or factual backing as well, leading to mass hoardings of the drug and diverting the drug from those who are in dire need of it towards use for treating COVID-19. This led to fears of worldwide shortage of Hydroxychloroquine as well as the ingredients used to prepare said drug. Public endorsements by certain political leaders of the drug also led to unauthorised personal consumption of the drug by nonexperts that led to further deaths, side effects and serious health implications. Even the WHO had stopped clinical trials of the drug citing that it didn't have any clinical benefits, reduce deaths or have benefits among moderate diseases.

One myth that has been making rounds since the beginning of the pandemic till even now is that consumption of alcohol, can cure the disease. Sure, alcohol-based hand sanitisers work well in disinfecting the skin, but the same can't be said if it is consumed. Afterall, hand sanitisers are not meant for human consumption in the first place. Regardless, in numerous people have fallen for the hoax and have consumed alcohol-based sanitisers believing that it will prevent the disease, but alas, countless have died from the consumption. The WHO website even warns against consumption of alcohol, which can cause health problems. 
Another variation of the alcohol-based sanitiser consumption hoax is that of injecting or consuming other disinfectants like bleach and chlorine. Despite repeated warnings from various sources, there have been cases of direct consumption or injecting bleach and chlorine. Such form of consumption is severely harmful for the body, causing damage to tissues, blood vessels and organs leading to even death, and perhaps a fast one at that. Even application of bleach and chlorine on the skin is harmful and damaging, especially if it enters the mouth, eyes or other delicate parts.

The fact that many patients suffering from COVID-19 also develop pneumonia as a health complication of the former disease has led to spurious claims of vaccines against pneumonia, such as the pneumococcal vaccine and Haemophilus influenza type B (Hib) vaccine, providing immunity against the SARS-CoV-2 virus. However, the virus is a relatively new strain that needs its own vaccine, which researchers are racing to develop. The SARS-CoV-2 virus can't be protected against by using existing vaccines, but the WHO still recommends for immunising and vaccinating against respiratory illnesses as an added precaution. (6)

Medical personnel serve as an inspiration to others in taking preventive measures, and seeing them wearing masks enable others to follow the same. Wearing masks is highly encouraged, with penalties being applied in many places for those who don't follow the norm. While it is true that wearing masks reduce chances of contracting the virus, it is often a misconstrued belief inferred from the widely encouraged practice that wearing masks will guarantee prevention from being afflicted with COVID-19. Disposable and cloth masks protect wearers from droplets and other such body fluids that can spread the disease, but they offer little protection against aerosolised particles. Other masks like the N95 masks and surgical masks offer a greater degree of protection. However, no mask can offer guaranteed prevention from the disease, at least not by themselves. They need to be worn along with practicing other preventive measures. Another concern that turned into myths is that medical personnel who wear masks for long durations are at an increased risk of $\mathrm{CO} 2$ poisoning or oxygen deprivation, but none of these are true. Properly and tightly fixed masks provide sufficient breathing capability to the wearer with no risk of oxygen shortage or intoxication of $\mathrm{CO} 2$. The WHO does, however, recommend against wearing masks while exercising as it may lead to excessive sweating leading to growth of microbes within the mask, but maintaining a minimum distance of 1 meter against others is advised.

Emergence of COVID-19 had developed interest in measures like gargling and rinsing nostrils with salt water as a preventive measure or even a possible cure to rid one's upper respiratory tract of the virus. While there is some proof that such activities may alleviate certain symptoms and help in quicker recovery from common cold, no results have come forth proving that it can prevent, cure or reduce chances of a COVID-19 infection.

Over the months there has been a trend of people posting on social media handles, claims that consumption of various homemade remedies such as ginger, garlic, Vitamin C, turmeric, healthy and essential oils etc. can all cure COVID-19. Another such instance includes spurious WhatsApp forwarded messages claiming that the disease is perfectly curable using such homemade food items and simple remedies. It is particularly those of simpler minds or those belonging to poorer backgrounds with insufficient knowledge 
or those belonging to older age groups who aren't familiar with technology and easily fall for such claims. Most of these food items may actually be good for the health, but they don't cure the disease or prevent its transmission. Spreading such misinformation not only causes patients to rely on such measures instead of opting for appropriate medical care, but also creates a lax nature that cause people to take the issue lightly.

Similar to the fake news spread on home remedies, another one is that other branches of medicine like homeopathy, Ayurveda, Unani etc. or activities like practicing yoga can help one rid oneself of the affliction. Apart from these myths being spread around, many of them have even been endorsed by people in influential positions, which is more harmful than being spread as mere rumours. They may benefit the human body in some form, but don't cure or immunise against COVID-19 and shouldn't be considered as such. Many quacks and people with fake medical degrees often sell questionable materials claiming them to be cures for COVID-19 as well, in order to scam unsuspecting victims. (7)

\section{Myths and Fake News Related to Symptoms and Suspected Cases}

Apart from bogus claims on transmissions and cures, rumours have also contributed to social stigmas and discrimination in the community against patients. Due to fears over contracting the disease from people who currently suffer from the same, patients are mistreated in many societies and communities, being isolated and singled out, with no one to come to their help. However, on a positive side, there have also been cases where people have come in together to provide any help to patients and get them back on their feet too.

Similar to discrimination against patients, rumours have also been spread to target medical personnel and other frontline workers, claiming that they help in spreading COVID-19 too $(8,-10)$.

While, this couldn't be any further from the truth, large number of people have started believing these. This has even led to further cases of vandalism of their properties as well as cases of violence and aggression against the frontline workers. This discrimination has even extended to the likes of migrant workers and labourers who wish to go back to their hometown. Apart from people, rumours have also targeted various businesses claiming that the employees working there are COVID19 positive. This has led to people boycotting those establishments. However, more often than not, those rumours are just that- rumours! Most work places are taking the disease seriously, enforcing social distancing norms, frequent regular cleaning and sanitising, having sanitisers installed for workers, thermal checking to keep an eye out for fever etc (11-13).

While not exactly a rumour or fake news, but the abundance of deaths and COVID19 positive cases being reported with other rumours going hand in hand to raise public fears, even the slightest symptoms of cold or fever are causing people to overreact to the situation. While it is sensible and rational for responsible people to take care of their health and remaining aware of their condition(14-16). It borders on hysteria when people get frightened that they have contracted the disease at the lightest sneeze or a cough or simple throat itch. While it is admirable that they take care of themselves, demanding to get checked for COVID-19 is a tad bit unreasonable, especially if there's no other serious symptoms or if they person has been following all safety precautions and there was no contact made with outsiders. (8)

While we have covered some of the myths, rumours and fake news that have been spread over the months through various 
facets of communication channels, it remains one's to be ever vigilant and protect oneself from such misinformation campaigns. While the COVID-19 pandemic is a scary affair with all the damage that it has done, the added false information multiplies that damage by many folds more. While we may have not yet understood the SARS-CoV-2 virus and made much progress in curing the disease, we still have control over what we choose to believe and what we choose to spread (17).

It is the responsibility of every individual to educate themselves about all the dos and don'ts about the disease from credible sources of information as well as fact checking any other information that they come across. Apart from not believing or avoiding spreading misinformation, it is also one's responsibility to act upon that information reasonable. The fact that spreading rumours and false news has led to countless instances of increased vandalism, aggression, xenophobia, discrimination, stigmatisation etc. goes on to show the irresponsible behaviour of people. Such acts against frontline workers who help grease the system for the society to function normally in such turbulent times is shameful, but so is it if it's against just about anybody else. Extended periods of lockdowns and being stuck at home is surely distressing for many people, but all the added rumours only contribute to further stress and pressure, even leading to instances of depression or other mental illnesses. Not choosing to obey lockdown rules or practicing safety measures is yet another gross negligence that has actually led to such a serious situation (18-20).

Various government and non-government bodies have enforced a number of measures to keep a check on proliferation of such false news. Penalties, fines and imprisonments are being implemented to discourage and punish people who are caught spreading such rumours. Social media websites such as Facebook and
Instagram have started taking actions against accounts that are suspected of spreading COVID-19 related myths. Apart from fictional claims related to the disease, various online platforms are also being created to tackle various other myths related to actions taken by government bodies that lead to large scale panic and resulting in hoarding and shortages. Such platforms disseminating information should also have them in a manner that is easy to understand by the massy public and the locals if it's a regional website.

\section{CONCLUSION:}

It is only with time that researchers will have a better understanding of the disease and we will be ready to tackle the pandemic, and may even have developed a vaccine. Until then, every individual should choose to follow all preventive and safety measures, make use of credible websites to fact check and also choose to act on that information sensible and reasonable, in a manner that they cause no form of harm, either to themselves or to others.

\section{REFERENCES:}

[1] Sánchez-Duarte JM, Rosa RM. Infodemia y COVID-19. Evolución y viralización de informaciones falsas en España. Revista española de comunicación en salud. 2020 Jul 16:31-41.

[2] Bakir V, McStay A. Fake news and the economy of emotions: Problems, causes, solutions. Digital journalism. 2018 Feb 7;6(2):154-75.

[3] Brown P. From rationalities to lifeworlds: Analysing the everyday handling of uncertainty and risk in terms of culture, society and identity.

[4] Karampela M, Ouhbi S, Isomursu M. Personal health data: A systematic mapping study. International journal 
of medical informatics. 2018 Oct 1;118:86-98.

[5] Hirvonen N, Tirroniemi A, Kortelainen T. The cognitive authority of user-generated health information in an online forum for girls and young women. Journal of Documentation. 2019 Jan 14.

[6] Ripoll-Vera T, Luengo CP, Alcázar JC, Ruiz AB, Del Valle NS, Martín BB, García JL, Buitrago GG, Martínez CD, Villena JC, Corvillo SM. Muerte súbita de jóvenes: rendimiento diagnóstico de un programa autonómico de autopsia molecular con secuenciación masiva. Revista Española de Cardiología. 2020 May 24.

[7] Krauss E. Desenvolvimento de metodologia para monitoramento contínuo da concentração de emissão de PM1 em fontes estacionárias industriais.

[8] Kuhlthau C. Kuhlthau's information search process. InIn Fisher et al.[18 2005.

[9] Srivastava, K.C., D. Shrivastava, K.G. Chhabra, W. Naqvi, and A. Sahu. "Facade of Media and Social Media during Covid-19: A Review." International Journal of Research in Pharmaceutical Sciences 11, no. Special Issue 1 (2020): 142-49. https://doi.org/10.26452/ijrps.v11iSP L1.2288.

[10] Bakshi, S., V. Toshniwal, A. Agrawal, S. Acharya, and S. Shukla. "Awareness and Psychosocial Effects of Covid-19 Pandemic on Health Care Professionals and Medical Students across the State of Maharashtra." International Journal of Current Research and Review 12, no. 22 Special Issue (2020): S-122-S125 .
https://doi.org/10.31782/IJCRR.2020 .SP74.

[11] Kaple, M.N., C. Mahakalkar, M. Philip, and S. Kshirsagar. "COVID 19 Pandemic: Social Aspects and Safe Behaviours." Journal of Critical Reviews 7, no. 8 (2020): 1066-69. https://doi.org/10.31838/jcr.07.08.22 2.

[12] Toshida, T., and C. Jagruti. "COVID-19 - Rumours and Facts in Media." International Journal of Research in Pharmaceutical Sciences 11, no. Special Issue 1 (2020): 17174.

https://doi.org/10.26452/ijrps.v11iSP L1.2344.

[13] Gaidhane, A., A. Sinha, M. Khatib, P. Simkhada, P. Behere, D. Saxena, B. Unnikrishnan, M. Khatib, M. Ahmed, and Q.S. Zahiruddin. "A Systematic Review on Effect of Electronic Media on Diet, Exercise, and Sexual Activity among Adolescents." Indian Journal of Community Medicine 43, no. 5 (2018): S56-65. https://doi.org/10.4103/ijcm.IJCM_1 43_18.

[14] Mandwar, S., S. Dharampuria, G. Nimbulkar, K.G. Chhabra, and A. Reche. "Misconceptions and Myths about COVID-19." International Journal of Research in Pharmaceutical Sciences 11, no. Special Issue 1 (2020): 1319-22. https://doi.org/10.26452/ijrps.v11iSP L1.3630.

[15] Masurkar, D., and P. Jaiswal. "Myths about COVID-19." International Journal of Research in Pharmaceutical Sciences 11, no. Special Issue 1 (2020): 907-12. https://doi.org/10.26452/ijrps.v11iSP L1.3124. 
[16] Mohod, S., S.S. Nemade, Y.S. Goenka, S.N. Jain, S.A. Patel, and K.G. Chhabra. "COVID-19: A Systematic Approach to Solve the Dilemma." International Journal of Research in Pharmaceutical Sciences 11, no. Special Issue 1 (2020): 133438.

https://doi.org/10.26452/ijrps.v11iSP L1.3632.

[17] Khatib, M.N., S. Gaidhane, M. Khatib, M. Ahmed, A. Gaidhane, and Z.Q. Syed. "SARS-CoV and SARSCoV-2: Similar Viruses with Different Trajectories." Wutan Huatan Jisuan Jishu 16, no. 5 (2020): 544-48.

[18] Muley, P.P., P.A. Muley, and K.A. Meshram. "Effect of COVID-19 Lockdown on Perceived Stress Scale in Medical Students.” Indian Journal of Forensic Medicine and Toxicology 14, no. 4 (2020): 642629. https://doi.org/10.37506/ijfmt.v14i4. 12611.

[19] Nisargandha, M.A., and S. Dadaraoparwe. "Spread of Coronavirus Disease 2019 (COVID19) during the Lockdown in the Indian Population and Preventive Measures." International Journal of Research in Pharmaceutical Sciences 11, no. Special Issue 1 (2020): 32832.

https://doi.org/10.26452/ijrps.v11iSP L1.2721.

[20] Wanjari, T.N., and G. Sawarkar. "Lockdown Lifestyle: Engaging the Invisible Enemy." International Journal of Research in Pharmaceutical Sciences 11, no. Special Issue 1 (2020): 491-95. https://doi.org/10.26452/ijrps.v11iSP L1.2836. 